\title{
A validated disease specific prediction equation for resting metabolic rate in underweight patients with COPD
}

This article was published in the following Dove Press journal: International Journal of Chronic Obstructive Pulmonary Disease I September 2010

Number of times this article has been viewed

\author{
Anita Nordenson ${ }^{2}$ \\ Anne Marie Grönberg',2 \\ Lena Hulthén' \\ Sven Larsson ${ }^{2}$ \\ Frode Slinde \\ 'Department of Clinical Nutrition, \\ Sahlgrenska Academy at University \\ of Gothenburg, Göteborg, Sweden; \\ ${ }^{2}$ Department of Internal Medicine/ \\ Respiratory Medicine and Allergology, \\ Sahlgrenska Academy at University \\ of Gothenburg, Sweden
}

\begin{abstract}
Malnutrition is a serious condition in chronic obstructive pulmonary disease (COPD). Successful dietary intervention calls for calculations of resting metabolic rate (RMR). One disease-specific prediction equation for RMR exists based on mainly male patients. To construct a disease-specific equation for RMR based on measurements in underweight or weight-losing women and men with COPD, RMR was measured by indirect calorimetry in 30 women and 11 men with a diagnosis of COPD and body mass index $<21 \mathrm{~kg} / \mathrm{m}^{2}$. The following variables, possibly influencing RMR were measured: length, weight, middle upper arm circumference, triceps skinfold, body composition by dual energy x-ray absorptiometry and bioelectrical impedance, lung function, and markers of inflammation. Relations between RMR and measured variables were studied using univariate analysis according to Pearson. Gender and variables that were associated with RMR with a $P$ value $<0.15$ were included in a forward multiple regression analysis. The best-fit multiple regression equation included only fat-free mass (FFM): RMR $(\mathrm{kJ} /$ day $)=1856+76.0 \mathrm{FFM}(\mathrm{kg})$. To conclude, FFM is the dominating factor influencing RMR. The developed equation can be used for prediction of RMR in underweight COPD patients.
\end{abstract}

Keywords: pulmonary disease, chronic obstructive, basal metabolic rate, malnutrition, body composition

\section{Introduction}

Chronic obstructive pulmonary disease (COPD) is one of the leading causes of death in Sweden as well as in many other countries. ${ }^{1-3}$ Women seem to be more susceptible than men to develop COPD, ${ }^{4,5}$ and in Sweden more women than men die from COPD. ${ }^{1}$ It has recently been shown that patients with COPD suffer a tremendous disease burden manifested by higher rates of all-cause and respiratory-related health care utilization and costs, and a high prevalence of comorbidities. ${ }^{6}$ Almost $50 \%$ of all COPD patients become underweight, and several studies have shown that a low body mass index (BMI) or body composition with low fat-free mass index (FFMI), is a major mortality risk factor. $^{7-9}$ In a previous study of our group we demonstrated a great variation in total energy expenditure, physical activity, energy intake and resting metabolic rate (RMR) among underweight patients with COPD living at home. ${ }^{10}$ It is important to estimate both the resting energy expenditure and the level of physical activity for approximation of the total energy needs in an individual patient. ${ }^{11}$ DLW (doubly labeled water) is considered to be the golden standard for assessment of total daily energy expenditure (TDE) but is too complicated and expensive to be performed in clinical praxis. RMR can be measured by indirect calorimetry, but this is not commonly an available method in the clinic. A reliable prediction equation of RMR is therefore of importance to establish
Correspondence: Frode Slinde Department of Clinical Nutrition, Sahlgrenska Academy, University of Gothenburg, PO Box 459, SE-405 30 Göteborg, Sweden Tel +46317863724 Fax +46317863101 Email frode.slinde@nutrition.gu.se 
an adequate nutritional support. There are several equations available to predict RMR, ie, WHO, ${ }^{12}$ Harris and Benedict, ${ }^{13}$ Moore and Angelillo, ${ }^{14}$ and Westerterp. ${ }^{15}$ The equation from Moore and Angelillo is the only one that is disease specific to predict RMR in COPD patients. It was developed based on a study with COPD patients with a majority of men. The aim of the present study was to develop a COPD-specific prediction equation for RMR in COPD patients with low body weight or great involuntary weight loss and to validate the equation in another group of COPD patients and to compare it with other prediction equations. We wanted the equation to be suitable for the clinical setting and to be based on RMR measurements in both men and women since earlier studies have mostly included men, and the problem with COPD in women is increasing.

\section{Materials and methods}

The Committee for Medical Research Ethics at University of Gothenburg approved the study. The patients were informed of the nature and purpose of the study and written informed consent was given.

\section{Patients}

The patients in this study and the validation group were both recruited from the out-patient unit at the Department of Respiratory Medicine, Sahlgrenska University Hospital, Göteborg, Sweden.

The inclusion criteria were: diagnosis of COPD, smoking history of $>10$ pack years, age over 45 years, a spirometry test performed during the last 12 months showing a $\mathrm{FEV}_{1} /$ FVC ratio less than 0.7 , FEV $1.0<60 \%$ of predicted normal and $\mathrm{BMI}<21 \mathrm{~kg} / \mathrm{m}^{2}$, or involuntary weight loss of $>10 \%$ over 3 months. Inclusion criteria for the validation group were the same except for the BMI criterion.

The exclusion criteria were inability to perform investigations without oxygen supply, inability to get to the hospital 3 times during 1 week, inability to contribute at the investigations, other severe diseases such as malignancy in an unstable phase, chronic heart failure, metabolic disease, or renal failure. Exclusion criteria for the validation group were the same with the addition of exclusion of patients with oxygen treatment at home.

\section{Study design}

The investigation for each patient took place during one week, and the patients visited the hospital on 3 different days. The patients had to be fasting during 12 hours before arrival to the hospital on all 3 visits. On arrival they were interviewed concerning any signs of infection during the last 2 weeks. If they reported any signs of infection during this period, the inclusion was postponed.

\section{Anthropometric measurements}

Length was measured to the nearest $0.5 \mathrm{~cm}$ using a horizontal headboard with an attached wall-mounted metric rule. Patients were weighed, without shoes and in underwear, on a digital balance to the nearest $0.1 \mathrm{~kg}$ (Weighcare, Newhaven, England). BMI was calculated as weight $(\mathrm{kg})$ divided by height $^{2}(\mathrm{~m})$. Middle upper arm circumference (MAC) was measured with a tape measure and triceps skinfold (TS) was measured with a Harpenden Skinfold Caliper $2 \mathrm{~cm}$ above midway between the acromion and olecranon; the average of 3 measurements was recorded.

\section{Pulmonary function tests}

Arterial blood gases (partial pressure of oxygen $\left(\mathrm{pO}_{2}\right)$ and partial pressure of carbon dioxide $\left(\mathrm{pCO}_{2}\right)$ ) were measured in all patients. Spirometry was performed on a spirometer SensorMedics model 922, (SensorMedics Co, Palm Springs, USA), except on the last patient where a spirometer Jaeger Masterscope (VIASYS, Hoechberg, Germany) was used. Prediction normal values according to the European Respiratory Society equations ${ }^{16}$ were used. In the study group, minute volume ( $\mathrm{L} \mathrm{min}^{-1}$ ) was also measured with equipment consisting of a Research Pneumotach System (RSS 100HR, Hans Rudolf, Kansas City, MO, USA) and a heated pneumotachygraph (type 3850AF and 3700A, Hans Rudolf). ${ }^{17}$

\section{RMR}

RMR was measured by indirect calorimetry using a ventilated-hood system at the first and second visit. The equipment used was a Deltatrac ${ }^{\mathrm{TM}}$ II Metabolic Monitor (Datex, Helsinki, Finland). Before each measurement, the equipment was calibrated with gas mixtures of known $\mathrm{O}_{2}$ and $\mathrm{CO}_{2}$ contents according to the manufacturer's instructions. All subjects were measured after an overnight fast. After a 30-minute rest in the supine position, RMR was measured during 30 minutes when the subjects were awake in the supine position. The measurements were performed in an environmental temperature between $22^{\circ} \mathrm{C}-23^{\circ} \mathrm{C}$. The presented mean RMR for each patient is based on the last 25 minutes of the measurement. The lowest RMR of the 2 measurement occasions was used as the outcome variable. RMR was then calculated in the study and validation group using the WHO equations. ${ }^{12}$ In the validation group, RMR 
was also calculated using the equations of Harris and Benedict, ${ }^{13}$ Moore and Angelillo, ${ }^{14}$ and Westerterp. ${ }^{15}$

\section{Body composition}

Body composition was measured with dual energy x-ray absorptiometry (DXA) (Lunar Prodigy, GE Lunar Corp, Madison, USA). In the validation group of COPD patients, body composition was also measured by single-frequency bioelectrical impedance assessment (BIA) in the morning after a 10 minute rest in the supine position. Impedance was measured by one single measurement of resistance (in ohms) and reactance (in ohms) with a BIA-101 equipment (Akern, Florence, Italy). The 4 electrodes were attached on the dorsal side of the foot, the ankle, the hand, and the wrist at the right side of the body. Fat-free mass (FFM) was calculated using manufacturer supplied equations based on comparison with densitometry in a normal population. FFMI was calculated as FFM (kg) divided by height ${ }^{2}(\mathrm{~m})$.

\section{Medication and nicotine use (study group)}

During 24 hours prior to the second visit, the patients registered every dose of nicotine and medication use.

\section{Markers of inflammation (study group)}

Levels of high-sensitive C-reactive protein (hs-CRP) were measured in serum with a latex reagent (Roche Diagnostics, Germany) using a modular PP analyzer (Roche, Japan) at the accredited laboratory at the Department of Clinical Chemistry, Sahlgrenska University Hospital. The intra-assay CV of the CRP method was $2 \%$ at $1 \mathrm{mg} / \mathrm{L}$ and $1 \%$ at $20 \mathrm{mg} / \mathrm{L}$. The amount of neutrophils was obtained from a blood differential test at the same laboratory.

High sensitivity ELISA was used to analyze tumor necrosis factor alpha (TNF- $\alpha$ ) (R\&D Systems HSTA00D) and Interleukin 6 (IL-6) (R\&D Systems HS600B) in serum.

\section{Statistics and validation}

Data are expressed as mean and standard deviations (SDs). To explore relations between RMR and possible measured variables, univariate analysis using Pearson correlation analysis were performed. Variables that were associated with RMR with a $P<0.15$ and gender were included in a forward multiple linear regression analysis. The prediction equation produced from this study was then validated in another sample of COPD patients. Both the FFM resulting from the DXA and the BIA were tested when validating the prediction equation. The validation was performed by paired $t$-tests and agreements plots, and the results from the newly produced equation were also compared with other existing RMR prediction equations.

\section{Results}

\section{Predicting BMR in COPD}

42 patients (31 women, 11 men) were included during the period February 2004 to December 2006. One patient (woman) with widespread lung cancer diagnosed after the first visit was excluded. Patient characteristics are presented in Table 1. The males had higher body weight, body height, BMI, and FFMI, compared with the females. 15 patients were active smokers, 5 patients used nicotine substitutes, and 6 patients were snuff users. The cigarette consumption in the smokers during 24 hours before RMR measurements was on average 11 cigarettes (range 1-23).

Variables related to RMR in the univariate analysis are presented in Table 2 . The best-fit multiple regression equation included only FFM and explains $64.7 \%$ of the variation in RMR, with a standard error of the estimate at $448.5 \mathrm{~kJ}$ :

$$
\operatorname{RMR}(\mathrm{kJ} / \text { day })=1856+76.0 \mathrm{FFM}(\mathrm{kg})
$$

\section{Validation and comparison with other prediction equations}

Validation was performed in a sample of 44 patients with COPD (29 women, 15 men). Patient characteristics are presented in Table 3 . The males had higher body height and FFMI compared with the females. The 2 patient samples were not statistically significantly different in age and body height, but differed with regard to body weight, BMI, FFMI, and $\mathrm{FEV}_{1}$. The new equation underestimates RMR using FFM assessed by DXA (Table 4). Since none of the patients in the original sample from where we produced the equation were obese, we decided to exclude patients with a BMI $>30 \mathrm{~kg} / \mathrm{m}^{2}$ ( 1 male and 2 females) from the validation material and redo the analysis. This resulted in an acceptable estimation of

Table I Patient characteristics, mean (SD)

\begin{tabular}{|c|c|c|c|c|}
\hline & $\begin{array}{l}\text { All subjects } \\
(n=4 I)\end{array}$ & $\begin{array}{l}\text { Female } \\
(n=30)\end{array}$ & $\begin{array}{l}\text { Male } \\
(n=I I)\end{array}$ & $P^{a}$ \\
\hline Age (years) & $63.5(8.8)$ & $62.9(8.6)$ & $65.2(9.4)$ & 0.47 \\
\hline Body weight (kg) & $52.4(7.8)$ & $49.7(6.7)$ & $59.7(5.6)$ & 0.000080 \\
\hline Body height $(\mathrm{cm})$ & $167.7(8.0)$ & $165.0(6.4)$ & $175.2(7.4)$ & 0.00010 \\
\hline BMI $\left(\mathrm{kg} / \mathrm{m}^{2}\right)$ & $18.8(2.0)$ & $18.5(2.1)$ & $19.8(1.1)$ & 0.045 \\
\hline $\mathrm{FEV}_{1}$ (\% predicted) & $39(15)$ & $40(15)$ & $36(15)$ & 0.48 \\
\hline FFMI $\left(\mathrm{kg} / \mathrm{m}^{2}\right)$ & $14.0(1.8)$ & $13.2(1.3)$ & $16.2(1.1)$ & 0.000000017 \\
\hline
\end{tabular}

Abbreviations: SD, standard deviation; BMl, body mass index; $\mathrm{FEV}_{1}$, forced expiratory volume in I second; FFMl, fat-free mass index.

anpaired $t$-test females versus males. 
Table 2 Pearson correlation coefficients reaching statistical significance $(P<0.05)$ between BMR $(k J)$ and other possible explaining factors measured

\begin{tabular}{ll}
\hline & $\begin{array}{l}\text { Correlation coefficient } \\
\text { with BMR }(\mathrm{kJ})\end{array}$ \\
\hline Fat free mass $(\mathrm{kg})$ & $0.799(P<0.0 \mathrm{I})$ \\
Body weight $(\mathrm{kg})$ & $0.714(P<0.0 \mathrm{I})$ \\
Body height $(\mathrm{m})$ & $0.709(P<0.0 \mathrm{I})$ \\
FVC $(\mathrm{L})$ & $0.562(P<0.0 \mathrm{I})$ \\
Package years & $0.443(P<0.0 \mathrm{I})$ \\
Arm circumference $(\mathrm{cm})$ & $0.419(P<0.0 \mathrm{I})$ \\
Minute volume $(\mathrm{L} / \mathrm{min})$ & $0.374(P<0.05)$ \\
BMI $\left(\mathrm{kg} / \mathrm{m}^{2}\right)$ & $0.369(P<0.05)$ \\
FEV $(\mathrm{L})$ & $0.334(P<0.05)$ \\
Neutrophiles $(\mathrm{n})$ & $-0.298(P=0.06)$ \\
Triceps skinfold $(\mathrm{mm})$ & $-0.269(P=0.09)$ \\
\hline
\end{tabular}

Abbreviations: BMR, basal metabolic rate; FVC, forced vital capacity; BMI, body mass index; FEV , forced expiratory volume in I second.

BMR, on group level, both when using the FFM from DXA and BIA (Table 4). The equations from WHO, ${ }^{12}$ Westerterp, ${ }^{15}$ and Moore and Angelillo ${ }^{14}$ clearly overestimates RMR and were therefore not analyzed in agreement plots.

Figure 1 illustrates the difference between measured and predicted RMR. There are small differences in agreement between the different equations shown. The current equation using FFM from DXA underestimates RMR by 131 (SD 563) kJ while using FFM from BIA induces an overestimation of 68 (SD 505) kJ. This could be compared to the Harris and Benedict equation, which overestimates RMR by 42 (SD 494) kJ. There are no systematic patterns of the agreements over the range of RMR in either of the equations; hence we conclude that each of the 3 variants predicts RMR as good as another.

\section{Discussion}

The main finding of the present study is that FFM explained $64.7 \%$ of the inter-individual variation in resting metabolic rate. Body weight, body height, FVC, package years, arm

Table 3 Patient characteristics of the validation population, mean (SD)

\begin{tabular}{lllll}
\hline & $\begin{array}{l}\text { All subjects } \\
(\mathbf{n}=\mathbf{3 7})\end{array}$ & $\begin{array}{l}\text { Female } \\
(\mathbf{n}=\mathbf{2 6})\end{array}$ & $\begin{array}{l}\text { Male } \\
(\mathbf{n}=\mathrm{II})\end{array}$ & $\mathbf{P}^{\mathrm{a}}$ \\
\hline Age (years) & $66.5(7.2)$ & $66.0(7.3)$ & $67.9(6.8)$ & 0.46 \\
Body weight $(\mathrm{kg})$ & $65.7(15.5)^{\mathrm{b}}$ & $62.7(13.6)$ & $72.7(15.2)$ & $0.07 \mathrm{I}$ \\
Body height $(\mathrm{cm})$ & $165.6(8.2)$ & $162.0(6.3)$ & $174.3(5.1)$ & 0.0000020 \\
BMI $\left(\mathrm{kg} / \mathrm{m}^{2}\right)$ & $23.8(4.2)^{\mathrm{b}}$ & $23.8(4.0)$ & $23.8(4.8)$ & 1.0 \\
FEV $(\% \mathrm{predicted})$ & $44(15)$ & $45(16)$ & $42(15)$ & 0.67 \\
FFMI $\left(\mathrm{kg} / \mathrm{m}^{2}\right)$ & $15.4(2.1)^{\mathrm{b}}$ & $14.7(1.4)$ & $17.0(2.5)$ & $0.0009 \mathrm{I}$ \\
\hline
\end{tabular}

anpaired $t$-test females versus males. ${ }^{\mathrm{b} P}<0.0 \mathrm{l}$ (unpaired $t$-test, validation population versus prediction population).

Abbreviations: SD, standard deviation; BMl, body mass index; $\mathrm{FEV}$, forced expiratory volume in I second; FFMI, fat-free mass index.
Table 4 Measured and predicted BMR in a validation population of COPD patients $(n=37)$, and in the same sample of COPD patients where the obese patients have been excluded $(n=34)$, mean (SD)

\begin{tabular}{|c|c|c|c|c|}
\hline & $\begin{array}{l}\text { BMR (kJ) } \\
(n=37)\end{array}$ & $P^{a}$ & $\begin{array}{l}\text { BMR (kJ) } \\
(n=34)\end{array}$ & $P^{a}$ \\
\hline Measured BMR & $5399(1205)$ & - & $5193(890)$ & - \\
\hline Current equation, using & $5 \mid 40(783)$ & 0.049 & $5062(72 I)$ & 0.23 \\
\hline \multicolumn{5}{|l|}{ FFM from DXA } \\
\hline Current equation, using & $5393(822)^{\mathrm{b}}$ & 0.91 & $5259(676)^{c}$ & 0.26 \\
\hline \multicolumn{5}{|l|}{ FFM from BIA } \\
\hline Harris and Benedict ${ }^{13}$ & $5321(918)$ & 0.41 & $5182(760)$ & 0.90 \\
\hline $\mathrm{WHO}^{12}$ & $5653(882)$ & 0.0010 & $5507(687)$ & 0.0015 \\
\hline $\begin{array}{l}\text { Westerterp }{ }^{15} \text { (based on } \\
\text { FFM from DXA) }\end{array}$ & $5767(1127)$ & 0.0017 & $5622(995)$ & 0.00039 \\
\hline Moore and Angelillo ${ }^{14}$ & $6169(1092)$ & $<0.001$ & $6012(955)$ & $<0.001$ \\
\hline
\end{tabular}

aPaired $t$-test between measured and predicted $B M R$. ${ }^{b} n=34$ due to technical error with the BIA. ${ }^{c} n=31$ due to technical error with the BIA.

Abbreviations: BMR, basal metabolic rate; COPD, chronic obstructive pulmonary disease; SD, standard deviation; FFM, fat-free mass; DXA, dual energy $x$-ray absorptiometry; BIA, bioelectrical impedance assessment.

circumference, breathing minute volume, BMI, FEV neutrophils, and triceps skin fold showed a lower degree of influence, and neither of the variables improved the strength of prediction. That FFM is the most important determinant of resting metabolic rate is in line with other studies. Creutzberg et al found in a study of 172 COPD patients that FFM explained $51 \%$ of the variation in resting energy expenditure. ${ }^{18}$ According to Schols et al FFM explained $84 \%$ of the variation in resting metabolic rate in a healthy control group and $34 \%$ of the variation in COPD patients. ${ }^{19}$ Both these studies, as well as the current study, included patients having severe or very severe COPD according to GOLD-guidelines. Although FFM seems to be the major factor predicting RMR in COPD patients, FFM does not seem to explain variations in RMR as well in COPD patients as in healthy individuals. This indicates that in COPD, factors other than FFM have larger impact on RMR than in healthy persons. We have however been unable to identify such factors in the current study. It should be noted that the patients in the current study had low FFMI. $55 \%$ of the males and $93 \%$ of the females had FFMI below the suggested reference values for COPD patients. ${ }^{20}$

The patients in our study seem to differ from those in other studies in that FFM explained more of the variation in RMR. This is especially evident in comparison with the study by Schols et al. ${ }^{19}$ Hypermetabolism has frequently been described in COPD patients especially in weight-losing patients in which measured RMR has been compared with RMR predicted according to the formula by Harris and Benedict. ${ }^{13}$ Our patient group differs also from these results. There was a close correlation between measured RMR and 
Current equation, using FFM from DXA

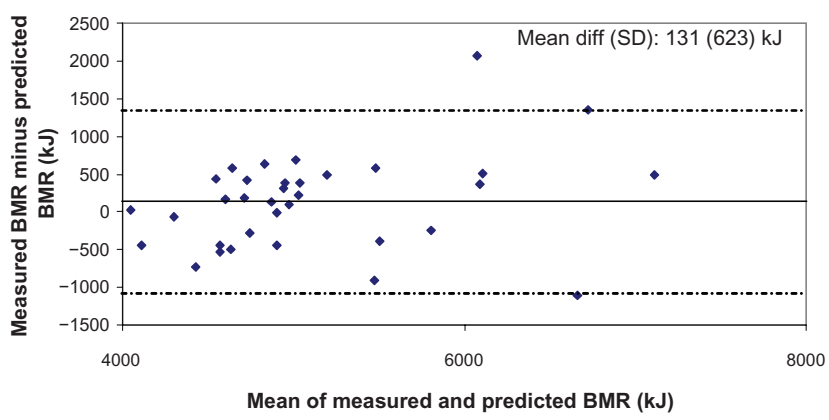

Current equation, using FFM from BIA
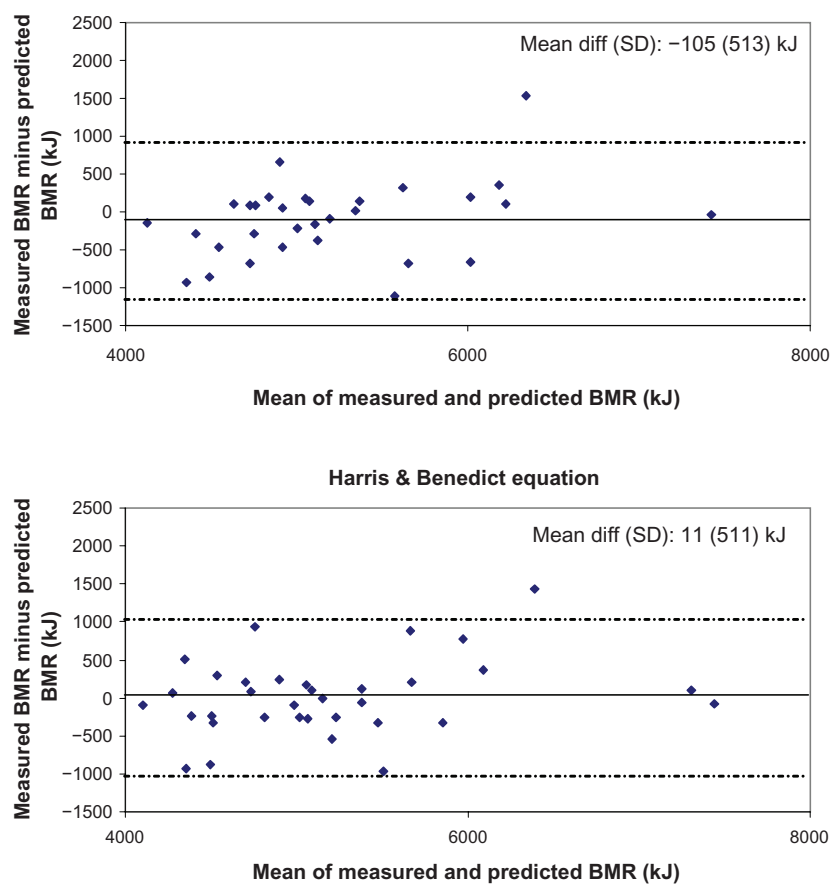

Figure I Mean of measured and predicted BMR

RMR predicted from the Harris and Benedict formula ${ }^{13}$ in our study. The disease-specific prediction formula by Moore and Angelillo ${ }^{14}$ on the other hand would have overestimated RMR in the present patient group as had the equations by $\mathrm{WHO}^{12}$ and Westerterp. ${ }^{15}$

The explanation for these differences between our patient group and other groups is not quite clear. It should be noted that we in this study have a relatively high proportion of women. The difference in the proportion of men and women in the studies seem to be of minor importance. Gender had little influence on RMR. Some possibly contributing factors may be mentioned. No patients with evidence of ongoing exacerbations were included in the present study. Only $36 \%$ of the patients were active smokers, and the amount of cigarettes smoked during the 24 hours before recording of RMR in those who smoked was only 11 cigarettes in average. It should however be noted that this result is based on self-report with no subjective marker of nicotine ingestion. Smoking habits were not reported in the other mentioned studies. Only 1 patient in our study was included because of known recent weight loss. We have, however, no information concerning the weight 1 year before entering the study of the remaining patients. The ratio of weight-losing/weight-stable patients is thus unknown. This could explain why the RMR in our patient group was lower than in the group of weight-losing COPD patients in the study mentioned above but not that RMR in our study group was lower than that of the weight-stable patients in that study. ${ }^{19} \mathrm{We}$ have also noted that systemic inflammation in our patient group seem to be less marked than in other studies. ${ }^{21}$ TNF- $\alpha$ was on average $2.5 \mathrm{pg} / \mathrm{mL}$ for male $(\mathrm{n}=11)$ and $1.6 \mathrm{pg} / \mathrm{mL}$ in female $(\mathrm{n}=30)$ subjects $(P=0.17)$. Our results might thus be influenced by few known weight-losing patients, few active smokers, and with evidence of less marked systemic inflammation than in other reported groups of COPD patients in other countries. Also, since the studied sample are relatively small, further validation studies in larger and more mixed population of COPD patients is needed to confirm the findings in this study.

The Harris and Benedict equation for predicting BMR gave results surprisingly similar to those produced with our prediction formula. The Harrison and Benedict equation is based on age, height, weight, and gender and developed from studies on normal healthy individuals in the first 2 decades of the 20th century. The average BMI in the Harris and Benedict population was $22 \mathrm{~kg} / \mathrm{m}^{2}$ when calculating BMI from average length and weight in the material collected from all series in the article. According to modern views, several of the persons included thus were underweight and in this respect similar to the present malnourished group of COPD patients. This might explain why the Harris and Benedict equation had the smallest difference compared with predicted RMR from our equation (Table 4), since the average BMI in our material also was low, $18.8 \mathrm{~kg} / \mathrm{m}^{2}$. The Harris and Benedict formula furthermore includes age as an important factor for predicting BMR. By increasing age, muscle mass diminishes, and as a result of that also RMR. Including age as a factor in a prediction formula thus indirectly uses FFM for prediction of RMR, which also might explain the close correlation with our prediction formula that is only based on FFM.

The results of the present study thus give further evidence to the view that RMR in COPD patients is not uniform. The prediction formula of this study seems to be best suited for malnourished but weight stable COPD patients. In patients still losing weight, our prediction formula might underestimate RMR. Actually measuring RMR is however recommended. 


\section{Grants}

The authors are grateful to The Swedish Heart Lung Foundation and The Swedish Heart and Lung Association for the financial support. The work was also supported by federal government grant according to the ALF agreement.

\section{Disclosure}

The authors report no conflicts of interest in this work.

\section{References}

1. Socialstyrelsen. National statistics. Causes of death in Sweden 1997-2006, 2010.

2. WHO. World health statistics 2008, 2008.

3. Hoyert DL, Heron MP, Murphy SL, et al. Deaths: Final Data for 2003. National Vital Statistics Report: Centers for Disease Control and Prevention, 2006.

4. Prescott E, Bjerg AM, Andersen PK, et al. Gender difference in smoking effects on lung function and risk of hospitalization for COPD: results from a Danish longitudinal population study. Eur Respir J. 1998;10:822-827.

5. Ben-Zaken Cohen S, Pare PD, Man SF, et al. The growing burden of chronic obstructive pulmonary disease and lung cancer in women: examining sex differences in cigarette smoke metabolism. Am J Respir Crit Care Med. 2007;176:113-120.

6. Sharafkhaneh A, Petersen NJ, Yu HJ, et al. Burden of COPD in a government health care system: a retrospective observational study using data from the US Veterans Affairs population. Int J Chron Obstruct Pulmon Dis. 2010;5:125-132.

7. Slinde F, Grönberg AM, Engström CP, et al. Body composition by bioelectrical impedance predicts mortality in chronic obstructive pulmonary disease patients. Respir Med. 2005;99:1004-1009.

8. Schols AM, Slangen J, Volovics L, et al. Weight loss is a reversible factor in the prognosis of chronic obstructive pulmonary disease. Am J Respir Crit Care Med. 1998;157:1791-1797.

9. Gray-Donald K, Gibbons L, Shapiro SH, et al. Nutritional status and mortality in chronic obstructive pulmonary disease. Am J Respir Crit Care Med. 1996;153:961-966.
10. Slinde F, Ellegård L, Grönberg AM, et al. Total energy expenditure in underweight patients with severe chronic obstructive pulmonary disease living at home. Clin Nutr. 2003;22:159-165.

11. Goris AH, Vermeeren MA, Wouters EF, et al. Energy balance in depleted ambulatory patients with chronic obstructive pulmonary disease: the effect of physical activity and oral nutritional supplementation. $\mathrm{Br} J$ Nutr. 2003;89:725-731.

12. FAO/WHO/UNU. Energy and protein requirements. Technical Report Series 724. Geneva: World Health Organization; 1985.

13. Harris JA, Benedict FG. A biometric study of basal metabolism in man. Publication 279. Washington DC: Carnegie Institute; 1919.

14. Moore JA, Angelillo VA. Equations for the prediction of resting energy expenditure in chronic obstructive lung disease. Chest. 1988;94: 1260-1263.

15. Westerterp KR, Donkers JH, Fredrix EW, et al. Energy intake, physical activity and body weight: a simulation model. Br J Nutr. 1995;73: 337-347.

16. Quanjer PH, Tammeling GJ, Cotes JE, et al. Lung volumes and forced ventilatory flows. Report Working Party Standardization of Lung Function Tests, European Community for Steel and Coal. Official Statement of the European Respiratory Society. Eur Respir J Suppl. 1993;16:5-40.

17. Bake B, Houltz B, Sjolund P. High tidal end expiratory flow - an index of dynamic hyperinflation? Clin Physiol Funct Imaging. 2007;27: 116-121.

18. Creutzberg EC, Schols AM, Bothmer-Quaedvlieg FC, et al. Prevalence of an elevated resting energy expenditure in patients with chronic obstructive pulmonary disease in relation to body composition and lung function. Eur J Clin Nutr. 1998;52:396-401.

19. Schols AM, Fredrix EW, Soeters PB, et al. Resting energy expenditure in patients with chronic obstructive pulmonary disease. Am J Clin Nutr. 1991;54:983-987.

20. Schols AM, Broekhuizen R, Weling-Scheepers CA, et al. Body composition and mortality in chronic obstructive pulmonary disease. Am J Clin Nutr. 2005;82:53-59.

21. Di Francia M, Barbier D, Mege JL, et al. Tumor necrosis factor-alpha levels and weight loss in chronic obstructive pulmonary disease. Am J Respir Crit Care Med. 1994;150:1453-1455.
International Journal of COPD

\section{Publish your work in this journal}

The International Journal of COPD is an international, peer-reviewed journal of therapeutics and pharmacology focusing on concise rapid reporting of clinical studies and reviews in COPD. Special focus is given to the pathophysiological processes underlying the disease, intervention programs, patient focused education, and self management protocols.

\section{Dovepress}

This journal is indexed on PubMed Central, MedLine and CAS. The manuscript management system is completely online and includes a very quick and fair peer-review system, which is all easy to use. Visit $\mathrm{http}: / /$ www.dovepress.com/testimonials.php to read real quotes from published authors. 